\title{
BMI modified the association of current smoking with the incidence of hypertension in Chinese population: a 22- year cohort study
}

Feifei Yao ${ }^{1+}$, Wenfeng $\mathrm{Liu}^{2+}$, Rencheng Zhao ${ }^{3}$, Guangxiao $\mathrm{Li}^{4}$, Xiaojuan Huang ${ }^{5}$ and Yongjie Chen ${ }^{6,7^{*}}$ (1)

\begin{abstract}
Background: There was little known on how the interaction effect between obesity and current smoking affected the incidence of hypertension. The aim of this study was to investigate how body mass index (BMI) modified the effect of current smoking on the incidence of hypertension.

Methods: Data were obtained from the China Health and Nutrition Survey (CHNS). According to the WHO recommendations for Chinese people, the normal weight, overweight, and obesity were defined using the BMI cutoff values $18.5 \mathrm{~kg} / \mathrm{m}^{2}, 23.0 \mathrm{~kg} / \mathrm{m}^{2}$, and $27.5 \mathrm{~kg} / \mathrm{m}$, respectively. Current smokers were defined as having smoked at least 100 cigarettes or electronic cigarettes, 20 cigars, or 20 tobacco pipes and other type of tobacco in the last 30 days preceding the survey. Hypertension was defined as systolic blood pressure (SBP)/ diastolic blood pressure $(D B P) \geq 140 / 90 \mathrm{mmHg}$, use of anti-hypertensive medications, or a self-reported diagnosis.

Results: This study included 12,900 subjects. There were interaction effects between obesity and current smoking in females $(P=0.030)$ and the $50-59$ years group $(P=0.049)$. Current smoking was a significant predictor of incident hypertension only in the total and female populations with normal weight (HR: 1.119 and 1.274; HR 95\% Cl: $1.013-1.236$ and 1.143-1.415; and $P=0.027$ and 0.040, respectively). Stratified by age, current smoking affected the development of hypertension only in the 50-59 years subjects with the normal weight (HR: 1.356; HR 95\% Cl: 1.084-1.697; and $P=0.008)$.
\end{abstract}

Conclusions: Current smoking was a significant predictor of incident hypertension only in the female and middle-age populations with normal weight but not in the overweight and obesity as well as the younger and elder populations.

Keywords: The interaction effect, Obesity, Current smoking, The incidence of hypertension

\footnotetext{
* Correspondence: chenyongjie@tmu.edu.cn

${ }^{\dagger}$ Feifei Yao and Wenfeng Liu contributed equally to this work.

${ }^{6}$ Department of Epidemiology and Statistics, School of Public Health, Tianjin

Medical University, 22 Qixiangtai Road, Tianjin, China

${ }^{7}$ Tianjin Key Laboratory of Environment, Nutrition and Public Health, 22

Qixiangtai Road, Tianjin, China

Full list of author information is available at the end of the article
}

(c) The Author(s). 2020 Open Access This article is licensed under a Creative Commons Attribution 4.0 International License, which permits use, sharing, adaptation, distribution and reproduction in any medium or format, as long as you give appropriate credit to the original author(s) and the source, provide a link to the Creative Commons licence, and indicate if changes were made. The images or other third party material in this article are included in the article's Creative Commons licence, unless indicated otherwise in a credit line to the material. If material is not included in the article's Creative Commons licence and your intended use is not permitted by statutory regulation or exceeds the permitted use, you will need to obtain permission directly from the copyright holder. To view a copy of this licence, visit http://creativecommons.org/licenses/by/4.0/ The Creative Commons Public Domain Dedication waiver (http://creativecommons.org/publicdomain/zero/1.0/) applies to the data made available in this article, unless otherwise stated in a credit line to the data. 


\section{Background}

As well known, hypertension, as a main chronic disease, has been the greatest attributable risk factor for death worldwide [1]. Moreover, hypertension is considered as a common risk predictor for cardiovascular disease (CVD) and accounts for approximately $45 \%$ of global CVD morbidity and mortality $[2,3]$. As a result, there were approximately 7 million hypertension-related deaths each year [4]. In China, the prevalence of hypertension increased from 14.5\% in 1991 to $34.0 \%$ in 2012 among adult population [5, 6]. As a result, it is an urgent need to take measurements to prevent and control the development of hypertension.

Many previous studies have reported that there is an association of adiposity with hypertension [7-10]. As the major independent risk factors for hypertension, overweight and obesity account for approximately $65-78 \%$ of adult hypertension cases $[8,11-13]$. On the other hand, smoking has been documented as a common risk factor for many chronic diseases, especially vascular dysfunction [14]. There was a well- established association of smoking with an increased risk of CVD $[15,16]$. According to the World Health Organization (WHO) report, smoking is the leading cause of 1.69 million CVD-related deaths [17]. The positive relationship between smoking and hypertension is also well established [18-21]. However, many previous studies reported that there was a long-run effect of smoking cessation on the weight gain [22, 23]. Evenly, there were some economic literatures to report that smoking can reduce BMI [24-26]. Therefore, there might be an interaction effect between obesity and smoking on the risk of hypertension.

However, there was little known on how the interaction effect between obesity and smoking affected the incidence of hypertension. In this study, it could therefore be hypothesized that there was a significant interaction between obesity and current smoking on the incidence of hypertension among adult population. The aim of this study was to investigate how obesity modified the effect of smoking on the incidence of hypertension.

Table 1 The characteristics of all subjects at baseline

\begin{tabular}{|c|c|c|c|c|c|}
\hline \multirow[t]{2}{*}{ Characteristics } & \multirow{2}{*}{$\begin{array}{l}\text { All subjects } \\
(12900)\end{array}$} & \multicolumn{2}{|l|}{ Subgroup subjects } & \multirow[t]{2}{*}{$t / x^{2}$} & \multirow[t]{2}{*}{$P$} \\
\hline & & Non-hypertension (8593) & Hypertension (4307) & & \\
\hline Age $\left(\right.$ year) ${ }^{a}$ & $38.14 \pm 14.31$ & $35.32 \pm 13.52$ & $43.75 \pm 14.19$ & -32.320 & $<0.001$ \\
\hline BMI $\left(\mathrm{kg} / \mathrm{m}^{2}\right)^{\mathrm{a}}$ & $21.78 \pm 2.81$ & $21.49 \pm 2.70$ & $22.34 \pm 2.95$ & -15.810 & $<0.001$ \\
\hline Sex & & & & 90.032 & $<0.001$ \\
\hline Male & $5885(45.62)$ & $3667(42.67)$ & $2218(51.50)$ & & \\
\hline Female & $7015(54.38)$ & $4926(57.33)$ & $2089(48.50)$ & & \\
\hline Current smoking & & & & 153.265 & $<0.001$ \\
\hline No & $7369(60.00)$ & $5126(64.00)$ & $2243(52.50)$ & & \\
\hline Yes & $4913(40.00)$ & $2884(36.00)$ & $2029(47.50)$ & & \\
\hline Current drinking & & & & 121.351 & $<0.001$ \\
\hline No & $7123(57.48)$ & $4936(61.05)$ & $2187(50.78)$ & & \\
\hline Yes & $5269(42.52)$ & $3149(38.95)$ & $2120(49.22)$ & & \\
\hline Ethnicity & & & & 59.812 & $<0.001$ \\
\hline Han & $10,906(84.54)$ & $7115(82.80)$ & 3791 (88.02) & & \\
\hline Other & $1994(15.46)$ & $1478(17.20)$ & $516(11.98)$ & & \\
\hline Physical activity & & & & 12.581 & $<0.001$ \\
\hline No & $12,268(95.10)$ & $8131(94.62)$ & $4137(96.05)$ & & \\
\hline Yes & $632(4.90)$ & $462(5.38)$ & $170(3.95)$ & & \\
\hline Obesity $^{b}$ & & & & 14.085 & $<0.001$ \\
\hline Normal & $9230(71.55)$ & $6477(75.38)$ & $2753(63.92)$ & & \\
\hline Overweight & $3181(24.66)$ & $1883(21.91)$ & $1298(30.14)$ & & \\
\hline Obesity & 489 (3.79) & $233(2.71)$ & $256(5.94)$ & & \\
\hline Death & & & & 5.096 & 0.024 \\
\hline No & $11,935(92.52)$ & 7982 (92.89) & 3953 (91.78) & & \\
\hline Yes & 965 (7.48) & $611(7.11)$ & $354(8.22)$ & & \\
\hline
\end{tabular}

${ }^{a}$ These variables were analyzed using $t$ test

${ }^{\mathrm{b}}$ This variable was analyzed using Wilcoxon rank sum test 


\section{Methods}

\section{Study design}

This study was based on the China Health and Nutrition Survey (CHNS), which is an open-cohort and national project [27]. The CHNS covers nine provinces, which are representative of the economic development and public resources in China. A multistage stratified random cluster process was employed to extract four counties from each province. A detailed description of the survey design has been published elsewhere [27, 28].

\section{Study population}

This study covered all nine waves of the CHNS conducted from 1989 to 2011. The studied subjects should meet the following criterions: who were aged $\geq 18$ years at baseline; who were with complete data on sex, weight, height, current smoking, and blood pressure. The subjects who were pregnant or lactating at the time of survey or with missing and implausible outlying data (e.g., weight $>300 \mathrm{~kg}$ or $<20 \mathrm{~kg}$ ) would be excluded.

\section{Measurement and definition of indicators}

Weight and height were measured by the trained healthcare workers following standardized protocols. The detailed measurements of weight and height have been described in the previous studies [8, 29]. BMI was calculated as weight in kilograms divided by the square of height in meters. Three measurements were conducted per subject for each indicator. And the average was used to analyze.

According to the WHO recommendations for Chinese people, the normal weight, overweight, and obesity were defined using the BMI cutoff values $18.5 \mathrm{~kg} / \mathrm{m}^{2}, 23.0 \mathrm{~kg} /$ $\mathrm{m}^{2}$, and $27.5 \mathrm{~kg} / \mathrm{m}^{2}$ [30]. Current smokers were defined as having smoked at least 100 cigarettes or electronic cigarettes, 20 cigars, or 20 tobacco pipes and other type of tobacco (such as chewing betel quid with tobacco, dipping tobacco, and snuff tobacco) in the last 30 days preceding the survey $[31,32]$. Nonsmokers were defined as they had never smoked in their lifetime. Former smokers were not mentioned in this study. Current drinking was defined as intake at least $50 \mathrm{~g}$ alcohol daily in the last 30 days prior to the survey [33]. Physical activity was defined as no (less than one hour per week) or yes (one or more hours per week). Under calm state, blood pressure measurements were taken with $30 \mathrm{~s}$ intervals between cuff inflations using standard mercury sphygmomanometers [34]. Cuff size was selected according to each participant's arm circumference. When the first and fifth Korotkoff sounds appeared, systolic blood pressure (SBP) and diastolic blood pressure (DBP) were recorded, respectively. The same measurements were conducted for three times and the average was used. Then, hypertension was defined as SBP/DBP $\geq 140 / 90$
$\mathrm{mmHg}$, use of anti-hypertensive medications, or a selfreported diagnosis of hypertension [34, 35].

\section{Statistical analysis}

Data are expressed as means \pm standard deviations (SDs) for continuous variables and frequencies (percentages) for categorical variables. The differences of the baseline characteristics between the non-hypertension and hypertension groups were compared by $t$-tests, chi-square tests, and Wilcoxon rank sum tests for continuous normal variables, categorical variables, and ordinal variables, respectively. With hypertension as the end-event, Cox regressions were employed to examine the interaction effects between obesity and smoking as well as the associations of obesity and current smoking with the incidence of hypertension. All models adjusted for death to correct the competing risk. All Cox regression models met the proportional hazard assumption. In the adjusted models, age, sex, current drinking, physical activity, and ethnicity at baseline were adjusted. When the interaction effects appeared, the single effects of obesity and current smoking were tested using Contrast statement in Phreg procedure of SAS with Bonferroni correction for multiple comparison. All analyses were conducted using SAS 9.4 (SAS Institute Inc., Cary, NC, USA.). The twotailed $P \leq 0.05$ was taken as the statistical significance.

\section{Results}

This study included 12,900 subjects, 4307 of who were hypertensive and 8593 subjects were non-hypertensive. The average of age was 38.14 years and BMI was 21.78

Table 2 The interaction effect between obesity and current smoking on the incidence of hypertension

\begin{tabular}{|c|c|c|c|c|}
\hline \multirow[t]{2}{*}{ The interaction terms } & \multicolumn{2}{|l|}{ Crude } & \multicolumn{2}{|c|}{ Adjusted $^{a}$} \\
\hline & $\bar{\beta}$ & $P$ & $\bar{\beta}$ & $P$ \\
\hline \multicolumn{5}{|l|}{ Total population } \\
\hline obesity xcurrent smoking & -0.172 & 0.001 & -0.113 & 0.034 \\
\hline \multicolumn{5}{|l|}{ Males } \\
\hline obesity $\times$ current smoking & -0.219 & 0.007 & -0.089 & 0.273 \\
\hline \multicolumn{5}{|l|}{ Females } \\
\hline obesity $\times$ current smoking & -0.406 & 0.002 & -0.280 & 0.030 \\
\hline \multicolumn{5}{|l|}{ Aged $18-29$ years } \\
\hline obesity $\times$ current smoking & -0.084 & 0.551 & -0.095 & 0.499 \\
\hline \multicolumn{5}{|l|}{ Aged $30-49$ years } \\
\hline obesity $\times$ current smoking & -0.110 & 0.180 & -0.111 & 0.180 \\
\hline \multicolumn{5}{|l|}{ Aged $50-59$ years } \\
\hline obesity $\times$ current smoking & -0.216 & 0.034 & -0.202 & 0.049 \\
\hline \multicolumn{5}{|l|}{ Aged 60 93 years } \\
\hline obesity xcurrent smoking & 0.115 & 0.418 & 0.120 & 0.398 \\
\hline
\end{tabular}

a In adjusted model, age, gender, current drinking, ethnicity, physical activity, and death were adjusted 
Table 3 The single effects of obesity and current smoking on the incidence of hypertension in total population

\begin{tabular}{|c|c|c|c|c|c|c|}
\hline & \multicolumn{3}{|l|}{ Crude } & \multicolumn{3}{|c|}{ Adjusted $^{a}$} \\
\hline & $\overline{H R}$ & $\mathrm{HR} 95 \% \mathrm{Cl}$ & $P$ & $\overline{H R}$ & $\mathrm{HR} 95 \% \mathrm{Cl}$ & $P$ \\
\hline Overweight and nonsmoking & 2.480 & $1.870-3.288$ & $<0.001$ & 1.990 & $1.500-2.640$ & $<0.001$ \\
\hline Obesity and nonsmoking & 3.700 & $3.148-4.349$ & $<0.001$ & 2.872 & $2.441-3.378$ & $<0.001$ \\
\hline Overweight and current smoking & 2.276 & $1.642-3.154$ & $<0.001$ & 1.878 & $1.354-2.604$ & $<0.001$ \\
\hline Obesity and current smoking & 3.396 & $2.792-4.131$ & $<0.001$ & 2.710 & $2.227-3.299$ & $<0.001$ \\
\hline Current smoking and normal weight & 1.346 & $1.248-1.451$ & $<0.001$ & 1.119 & $1.013-1.236$ & 0.027 \\
\hline Current smoking and overweight & 1.235 & $1.105-1.380$ & $<0.001$ & 1.056 & $0.930-1.198$ & 0.400 \\
\hline Current smoking and obesity & 0.917 & $0.705-1.192$ & 0.516 & 0.893 & $0.683-1.167$ & 0.406 \\
\hline
\end{tabular}

In adjusted model, age, sex, current drinking, ethnicity, physical activity, and death were adjusted

$\mathrm{kg} / \mathrm{m}^{2}$. The median of follow-up period was 8 years. The characteristics of all subjects are shown in Table 1. The differences of all characteristics between the nonhypertension and hypertension groups were significant.

Table 2 shows the interaction effect between obesity and current smoking on the incidence of hypertension. When adjusting for covariates, there were interaction effects between obesity and current smoking in the total population $(P=0.034)$, females $(P=0.030)$, and those aged $50-59$ years $(P=0.049)$. The further analyses were conducted to identify the single effects (Table 3 ). Without adjusting for covariates, overweight and obesity were associated with the incidence of hypertension despite of current smoking or not (all $P<0.001$ ). While current smoking was the risk factor of hypertension among the normal weight subjects (HR: 1.346; HR 95\% CI: $1.248-$ 1.451 ; and $P<0.001)$ and the overweight subjects (HR: 1.235; HR 95\% CI: 1.105-1.380; and $P<0.001$ ) but not among the obesity subjects (HR: 0.917; HR 95\% CI: $0.705-1.192$; and $P=0.516$ ). When adjusting for covariates, the effects of overweight and obesity were consistent with the crude results. But current smoking was a significant predictor of incident hypertension only among the normal weight subjects (HR: 1.119; HR 95\% CI: 1.013-1.236; and $P=0.027$ ).

In Cox regression models stratified by sex, there was no interaction effect between obesity and current smoking in males. Therefore, the single effects were displayed only in females (Table 4). As adjusting for covariates, overweight and obesity were the significant predictors of hypertension despite of current smoking or not (HR: 2.726, 3.074, 2.377, and 2.681; HR 95\% CI: 1.541-4.821, $2.570-3.678, \quad 1.161-4.867$, and 1.909-3.764; and $P<0.001,<0.001,0.018$, and $<0.001$, respectively). However, current smoking was associated with hypertension only in the normal weight subjects (HR: 1.274; HR 95\% CI: $1.143-1.415$; and $P=0.040)$, but not in the overweight $(P=0.851)$ and obesity subjects $(P=0.090)$.

The single effects of obesity and current smoking on the incidence of hypertension in the 50-59 years group are displayed in Fig. 1. Overweight and obesity were the predictors of hypertension except in the obesity subjects with nonsmoking (HR: 1.784; HR 95\% CI: 0.838-3.797; and $P=0.133$ ). And current smoking was a predictor of hypertension only among the normal weight subjects (HR: 1.356; HR 95\% CI: 1.084-1.697; and $P=0.008$ ).

\section{Discussion}

By now, there were few studies to investigate the interaction effect between obesity and current smoking on incident hypertension. This study was based on the CHNS, a 22-year national cohort study, and attempted to examine the interaction effect. The results implied that there were significant interaction effects between obesity and current smoking in females and the 50-59 years population. Despite of current smoking or not,

Table 4 The single effects of obesity and current smoking on the incidence of hypertension in females

\begin{tabular}{|c|c|c|c|c|c|c|}
\hline & \multicolumn{3}{|l|}{ Crude } & \multicolumn{3}{|c|}{ Adjusted $^{a}$} \\
\hline & $H R$ & HR 95\% Cl & $P$ & $H R$ & HR 95\% Cl & $P$ \\
\hline Overweight and nonsmoking & 3.345 & $1.893-5.912$ & $<0.001$ & 2.726 & $1.541-4.821$ & $<0.001$ \\
\hline Obesity and nonsmoking & 3.827 & $3.203-4.571$ & $<0.001$ & 3.074 & $2.570-3.678$ & $<0.001$ \\
\hline Overweight and current smoking & 2.623 & $1.282-5.364$ & 0.008 & 2.377 & $1.161-4.867$ & 0.018 \\
\hline Obesity and current smoking & 3.000 & $2.139-4.207$ & $<0.001$ & 2.681 & $1.909-3.764$ & $<0.001$ \\
\hline Current smoking and normal weight & 1.864 & $1.563-2.225$ & $<0.001$ & 1.274 & $1.143-1.415$ & 0.040 \\
\hline Current smoking and overweight & 1.462 & $1.147-1.862$ & 0.002 & 1.024 & $0.802-1.405$ & 0.851 \\
\hline Current smoking and obesity & 0.795 & $0.474-1.334$ & 0.386 & 0.639 & $0.381-1.072$ & 0.090 \\
\hline
\end{tabular}

${ }^{a}$ In adjusted model, age, current drinking, ethnicity, physical activity, and death were adjusted 


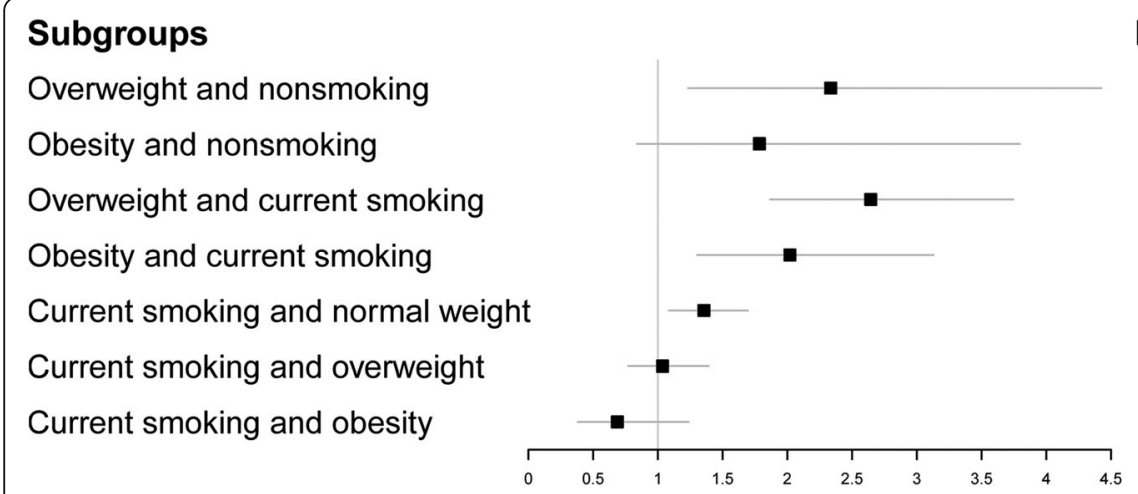

$\begin{array}{cc}\text { Harzard Ratio }(95 \% \text { Cl) } & \text { P value } \\ 2.335(1.233,4.425) & 0.009 \\ 1.784(0.838,3.797) & 0.133 \\ 2.644(1.867,3.745) & <0.001 \\ 2.020(1.304,3.129) & 0.002 \\ 1.356(1.084,1.697) & 0.008 \\ 1.036(0.771,1.392) & 0.814 \\ 0.687(0.381,1.237) & 0.211\end{array}$

Fig. 1 The single effects of obesity and current smoking on the incidence of hypertension in the 50-59 years group

obesity was a significant predictor of incident hypertension. However, current smoking was associated with hypertension only in the female and middle-aged subjects with the normal weight. When subjects were overweight or obesity, current smoking was ineffective on the incidence of hypertension.

Although previous studies reported that acute effect of smoking could temporarily raise blood pressure $[17,36$, 37], several population-based studies have shown that there was no or a negative relationship between chronic smoking and hypertension [38-40]. Perhaps obesity, as a confounding factor, covered the effect of smoking. Notably, the prevalence of smoking and hypertension have been decreasing, but accompanied with a simultaneous increase in obesity [41]. As a result, the effect of smoking on hypertension might reduce or disappear but the effect of obesity on hypertension would be more significant. However, the mechanism of the interaction effect between obesity and smoking is unknown and should be further investigated in the future study.

This study showed that current smoking was a significant risk factor for hypertension in females but not in males. It was consistent with the previous studies [19, 42]. A season might be the different characteristics between males and females. The characteristics of male smokers were smoking for a long time and heavy smoking but relatively lower proportion of smokers and hypertension in females [43].

\section{Limitations and strengths}

This study was based on a 22-year follow-up national population-based cohort study. As a result, the conclusion would be more comprehensive and convictive. Furthermore, it was the first study to examine the interaction effect between obesity and current smoking on the incidence of hypertension. The results would provide a new insight for prevention and control of hypertension. However, the limitations of this study should be stated. First, in this study, smoking status was obtained according to the self-reported questionnaire. There might be misclassification error and recall bias. Second, since the information of former smoking was unavailable, the former smoking was not considered in this study. Third, since the sodium intake is not available due to the limitation of the CHNS and the family history of hypertension is not collected in the CHNS, the diet intake and the family history of hypertension were not adjusted in this study.

\section{Conclusions}

Overweight and obesity were associated with the higher incident hypertension both in the smokers and the nonsmokers. However, current smoking was a significant predictor of the incidence of hypertension only in the female and middle-aged populations with the normal weight but not in the overweight and obesity as well as the younger and elder populations. Therefore, different public health interventional measurements should be made for different populations.

\section{Abbreviations}

CHNS: China Health and Nutrition Survey; CVD: Cardiovascular disease; SDs: Standard deviations; WHO: World Health Organization

\section{Acknowledgements}

Not applicable.

\section{Authors' contributions}

YC designed the study and wrote the draft, FY revised the manuscript and improved the language, WL analyzed the data, RZ interpreted the results, and $\mathrm{XH}$ and $\mathrm{GL}$ edited and reviewed the manuscript. All authors read and approved the final manuscript.

\section{Funding}

This work was supported by the National Natural Science Foundation of China (81903416) and the Science and Innovation Bureau Project of Baoan District, Shenzhen (2017JD150). The funding bodies did not play roles in the design of the study and collection, analysis, and interpretation of data and in writing the manuscript. Furthermore, we thank the National Institute for Nutrition and Health, China Center for Disease Control and Prevention, Carolina Population Center (P2C HD050924, T32 HD007168), the University of North Carolina at Chapel Hill, the NIH (R01-HD30880, DK056350, R24 HD050924, and R01-HD38700) and the NIH Fogarty International Center (D43 TW009077, D43 TW007709) for financial support for the CHNS data collection 
and analysis files from 1989 to 2015 and future surveys, and the China-Japan Friendship Hospital, Ministry of Health for support for CHNS 2009, Chinese National Human Genome Center at Shanghai since 2009, and Beijing Municipal Center for Disease Prevention and Control since 2011.

\section{Availability of data and materials}

The datasets analyzed during the current study are available in the China Health and Nutrition Survey (CHNS) on the site: https://www.cpc.unc.edu/ projects/china.

\section{Ethics approval and consent to participate}

This study was approved by the IRB of the National Institute for Nutrition and Food Safety, China Center for Disease Control and Prevention, and University of North Carolina at Chapel Hill. All subjects provided the written informed consent.

\section{Consent for publication}

Not applicable.

\section{Competing interests}

The authors declare that they have no competing interests.

\section{Author details}

${ }^{1}$ The office of the top tertiary hospital, Shekou People's Hospital, Nanshan district, Shenzhen, Guangdong Province, China. ${ }^{2}$ Center for Disease Control and Prevention of Changshan County, Quzhou, Zhejiang Province, China. ${ }^{3}$ Department of Chronic Non-communicable Diseases, Baoan Chronic Diseases Prevent and Cure Hospital, Shenzhen, Guangdong Province, China ${ }^{4}$ The Medical Record Center of the First Affiliated Hospital of China Medical University, Shenyang, Liaoning Province, China. ${ }^{5}$ Health Inspection Institute of Changshan County, Quzhou, Zhejiang Province, China. ${ }^{6}$ Department of Epidemiology and Statistics, School of Public Health, Tianjin Medical University, 22 Qixiangtai Road, Tianjin, China. ${ }^{7}$ Tianjin Key Laboratory of Environment, Nutrition and Public Health, 22 Qixiangtai Road, Tianjin, China.

Received: 3 September 2019 Accepted: 28 February 2020

Published online: 06 March 2020

\section{References}

1. Attard SM, Herring AH, Zhang B, Du S, Popkin BM, Gordon-Larsen P. Associations between age, cohort, and urbanization with systolic and diastolic blood pressure in China: a population-based study across 18 years. J Hypertens. 2015;33(5):948

2. Ezzati M, Vander Hoorn S, Lawes CM, Leach R, James WPT, Lopez AD, et al. Rethinking the "diseases of affluence" paradigm: global patterns of nutritional risks in relation to economic development. PLoS Med. 2005;2(5):e133.

3. Gać P, Poręba M, Mazur G, Poręba R. The aortic mechanical properties in patients with the essential hypertension environmentally exposed to cigaret smoke. Inhal Toxicol. 2015;27(13):717-23.

4. Ezzati M, Lopez AD, Rodgers A, Vander Hoorn S, Murray CJ, Group CRAC Selected major risk factors and global and regional burden of disease. Lancet. 2002;360(9343):1347-60.

5. Wu X, Duan X, Gu D, Hao J, Tao S, Fan D. Prevalence of hypertension and its trends in Chinese populations. Int J Cardiol. 1995:52(1):39-44.

6. Li D, LV J, Liu F, Liu P, Yang X, Feng Y, et al. Hypertension burden and control in mainland China: analysis of nationwide data 2003-2012. Int J Cardiol. 2015;184:637-44

7. Chandra A, Neeland IJ, Berry JD, Ayers CR, Rohatgi A, Das SR, et al. The relationship of body mass and fat distribution with incident hypertension: observations from the Dallas heart study. J Am Coll Cardiol. 2014;64(10): 997-1002.

8. Chen $Y$, Liang $X$, Zheng $S$, Wang $Y$, Lu W. Association of body fat mass and fat distribution with the incidence of hypertension in a population-based Chinese cohort: a 22-year follow-up. J Am Heart Assoc. 2018;7(6):e007153.

9. Chen $Y$, Liang $X$, Zheng $S$, Wang $Y$, Lu W. The comparison of percent body fat estimated by different anthropometrics to predict the incidence of hypertension. J Hum Hypertens. 2020;34(1):51-8.

10. Wang S, Liu Y, Li F, Jia H, Liu L, Xue F. A novel quantitative body shape score for detecting association between obesity and hypertension in China. BMC Public Health. 2015;15(1):7.
11. Garrison RJ, Kannel WB, Stokes J 3rd, Castelli WP. Incidence and precursors of hypertension in young adults: the Framingham offspring study. Prev Med. 1987;16(2):235-51.

12. Rahmouni K, Correia ML, Haynes WG, Mark AL. Obesity-associated hypertension: new insights into mechanisms. Hypertension. 2005;45(1):9-14

13. Xie D, Bollag WB. Obesity, hypertension and aldosterone: is leptin the link? J Endocrinol. 2016:230(1):F7-F11.

14. Li N, Li Z, Chen S, Yang N, Ren A, Ye R. Effects of passive smoking on hypertension in rural Chinese nonsmoking women. J Hypertens. 2015; 33(11):2210-4.

15. Berry JD, Dyer A, Cai X, Garside DB, Ning H, Thomas A, et al. Lifetime risks of cardiovascular disease. N Engl J Med. 2012;366(4):321-9.

16. Lloyd-Jones DM, Leip EP, Larson MG, d'Agostino RB, Beiser A, Wilson PW, et al. Prediction of lifetime risk for cardiovascular disease by risk factor burden at 50 years of age. Circulation. 2006;113(6):791-8.

17. Lee $\mathrm{W}, \mathrm{H}$ wang $\mathrm{S}-\mathrm{H}$, Choi $\mathrm{H}$, Kim H. The association between smoking or passive smoking and cardiovascular diseases using a Bayesian hierarchical model: based on the 2008-2013 Korea community health survey. Epidemiol Health. 2017;39:e2017026.

18. Dochi M, Sakata K, Oishi M, Tanaka K, Kobayashi E, Suwazono Y. Smoking as an independent risk factor for hypertension: a 14-year longitudinal study in male Japanese workers. Tohoku J Exp Med. 2009;217(1):37-43.

19. Bowman TS, Gaziano JM, Buring JE, Sesso HD. A prospective study of cigarette smoking and risk of incident hypertension in women. J Am Coll Cardiol. 2007;50(21):2085-92.

20. Niskanen L, Laaksonen DE, Nyyssönen K, Punnonen K, Valkonen V-P, Fuentes $R$, et al. Inflammation, abdominal obesity, and smoking as predictors of hypertension. Hypertension. 2004;44(6):859-65.

21. Mann SJ, James GD, Wang RS, Pickering TG. Elevation of ambulatory systolic blood pressure in hypertensive smokers: a case-control study. JAMA. 1991; 265(17):2226-8.

22. Flegal KM, Troiano RP, Pamuk ER, Kuczmarski RJ, Campbell SM. The influence of smoking cessation on the prevalence of overweight in the United States. N Engl J Med. 1995;333(18):1165-70.

23. Travier N, Agudo A, May AM, Gonzalez C, Luan J, Wareham NJ, et al. Longitudinal changes in weight in relation to smoking cessation in participants of the EPIC-PANACEA study. Prev Med. 2012;54(3-4):183-92.

24. Kasteridis $P$, Yen ST. Smoking cessation and body weight: evidence from the behavioral risk factor surveillance survey. Health Serv Res. 2012;47(4): 1580-602.

25. Kasteridis P, Yen ST. Occasional smoking and body weight among adults. Appl Econ Perspect Policy. 2014;36(3):479-503.

26. Amialchuk A, Bornukova K, Ali MM. Will a decline in smoking increase body weights? Evidence from Belarus. East Econ J. 2018;44(2):190-210.

27. Popkin BM, Du S, Zhai F, Zhang B. Cohort profile: the China health and nutrition survey-monitoring and understanding socio-economic and health change in China, 1989-2011. Int J Epidemiol. 2010;39(6):1435-40.

28. Zhao R, Duan X, Wu Y, Zhang Q, Chen Y. Association of exposure to Chinese famine in early life with the incidence of hypertension in adulthood: a 22-year cohort study. Nutr Metab Cardiovasc Dis. 2019;29(11): 1237-44.

29. Chen $Y$, Yang $Y$, Jiang $H$, Liang $X$, Wang $Y$, Lu W. Associations of BMI and waist circumference with all-cause mortality: a 22-year cohort study. Obesity. 2019;27(4):662-9.

30. Expert Consultation WHO. Appropriate body-mass index for Asian populations and its implications for policy and intervention strategies. Lancet. 2004;363(9403):157-63.

31. Wang J, Li C, Jia C, Liu Y, Liu J, Yan X, et al. Smoking, smoking cessation and tobacco control in rural China: a qualitative study in Shandong Province. BMC Public Health. 2014;14(1):916.

32. Sinha D, Palipudi K, Jones C, Khadka B, Silva P, Mumthaz M, et al. Levels and trends of smokeless tobacco use among youth in countries of the World Health Organization South-East Asia region. Indian J Cancer. 2014;51(5):50.

33. Wu L, Feng $X$, He A, Ding $Y, Z$ Zhou $X, X u Z$. Prenatal exposure to the great Chinese famine and mid-age hypertension. PLoS One. 2017;12(5):e0176413.

34. Chobanian AV. Joint National Committee on prevention, detection, evaluation, and treatment of high blood pressure; National Heart, Lung, and Blood Institute; National High Blood Pressure Education Program Coordinating Committee: seventh report of the joint National Committee on prevention, detection, evaluation, and treatment of high blood pressure. Hypertension. 2003;42:1206-52. 
35. Chobanian AV, Bakris GL, Black HR, Cushman WC, Green LA, Izzo JL Jr, et al. The seventh report of the joint National Committee on prevention, detection, evaluation, and treatment of high blood pressure: the JNC 7 report. JAMA. 2003:289(19):2560-72.

36. Yarlioglues M, Kaya MG, Ardic I, Calapkorur B, Dogdu O, Akpek M, et al. Acute effects of passive smoking on blood pressure and heart rate in healthy females. Blood Press Monit. 2010;15(5):251-6.

37. Schiess R, Senn O, Fischler M, Huber LC, Vatandaslar S, Speich R, et al. Tobacco smoke: a risk factor for pulmonary arterial hypertension?: a casecontrol study. Chest. 2010;138(5):1086-92.

38. Thuy AB, Blizzard L, Schmidt MD, Luc PH, Granger RH, Dwyer T. The association between smoking and hypertension in a population-based sample of Vietnamese men. J Hypertens. 2010;28(2):245-50

39. Wang W, Lee ET, Fabsitz RR, Devereux R, Best L, Welty TK, et al. A longitudina study of hypertension risk factors and their relation to cardiovascular disease: the strong heart study. Hypertension. 2006;47(3):403-9.

40. Primatesta P, Falaschetti E, Gupta S, Marmot MG, Poulter NR. Association between smoking and blood pressure: evidence from the health survey for England. Hypertension. 2001;37(2):187-93.

41. Smith CY, Bailey KR, Emerson JA, Nemetz PN, Roger VL, Palumbo PJ, et al. Contributions of increasing obesity and diabetes to slowing decline in subclinical coronary artery disease. J Am Heart Assoc. 2015;4(4):e001524.

42. Burke GM, Genuardi M, Shappell H, D'Agostino RB Sr, Magnani JW. Temporal associations between smoking and cardiovascular disease, 1971 to 2006 (from the Framingham heart study). Am J Cardiol. 2017;120(10): 1787-91.

43. Kim BJ, Han JM, Kang JG, Kim BS, Kang JH. Association between cotinineverified smoking status and hypertension in 167,868 Korean adults. Blood Press. 2017;26(5):303-10.

\section{Publisher's Note}

Springer Nature remains neutral with regard to jurisdictional claims in published maps and institutional affiliations.

Ready to submit your research? Choose BMC and benefit from:

- fast, convenient online submission

- thorough peer review by experienced researchers in your field

- rapid publication on acceptance

- support for research data, including large and complex data types

- gold Open Access which fosters wider collaboration and increased citations

- maximum visibility for your research: over $100 \mathrm{M}$ website views per year

At $\mathrm{BMC}$, research is always in progress.

Learn more biomedcentral.com/submissions 